\title{
The Printing of Mathematical Tables
}

1. Introduction. The printing of extensive mathematical tables requires perfection in accuracy and legibility, and economy of cost and skilled personnel. The printing of nineteen successive volumes of the American Air Almanac since 1940 has brought forward several notable developments in the art as woll as considerable interesting data on the comparison of different methods. The most recent development is a new table printing machine which combines the attributes of economy and perfection.

The printing of the American Air Almanac is a task of some magnitude, considering the high standards of perfection which are required. There are three volumes each year with a total of 730 pages each containing about 3,000 figures. Some editions have run to nearly two hundred thousand copies and it has been necessary on occasion to make successive reprints of a given volume. The assurance of perfection in millions of copies with billions of figures requires great care, especially under wartime printing conditions.

The need for perfection in the American Air Almanac is obvious. An erroneous figure could cause the loss of a valuable plane and crew. The figures must be easily legible since the aviator must read them quickly in a bouncing plane with poor illumination when he is tired, cold and short of oxygen. The volumes must be compact since they must be used in cramped quarters.

While the cost in money of the Air Almanac is not the primary consideration, the possible economies are not negligible, and the shortage of competent personnel during the war made the economy of effort a prime factor in providing adequate tables at the proper time. The time factor is important since the possibility of change in the Almanac makes it undesirable to prepare the volumes too far in advance.

2. Methods Used. In printing the nineteen successive volumes of the Air Almanac, four different methods have been used and complete records kept so that objective comparison is possible. These methods include both the setting of type and the preparation of manuscript for photographic reproduction without the use of type. The photographic reproduction has been done by the lithographic process and also by the use of zinc etchings or line cuts. The manuscript has been prepared both by a special process using an electric punched card accounting machine and by the new device recently built for the Naval Observatory by the International Business Machines Corporation.

The three volumes for 1941 were printed from movable type. As is well known the art of printing from such type is very highly developed and the impressions obtained are of the highest perfection in sharpness and clarity. The loose type and rules permit many refinements of composition, but the method is not economical either in cost or in the efforts required of the authors to secure perfection. Not only are errors frequent in setting the type but there is the possibility of error both while corrections are being made and even during the printing itself. In reading the first proofs of these $\mathbf{7 3 0}$ pages 840 errors were found. These were marked for correction, 
but when the revised proofs were examined, 68 errors were still present, many of them due to faulty correction of the previous errors.

The 840 errors in the first proofs averaged only a little over one to a page, which is quite acceptable when tables are computed and the copy prepared by hand, since the copy itself frequently contains about the same number of errors. The checks by differencing applied to such tables locate both types of error at the same time. In the case of the Air Almanac, however, the computation and preparation of the copy was performed automatically by means of punched card machines, which gave results of a much higher order of accuracy. The checks by differencing in this case revealed errors almost entirely due to the printer, only about one error in a thousand being due to the machines. The successive proof-reading of all the figures, to eliminate typographical errors from such perfect data, is not only costly. but is demoralizing.

For several reasons the books for 1941 were printed directly from the movable type, although it is customary, with large editions or where perfection requires it, to make electroplates from the type and to print from these plates. The use of such plates insures great reliability provided the plate proofs are adequately checked. Electroplates are used on the American Nautical Almanac and on the American Ephemeris and Nautical Almanac.

In addition to the method described above of setting the figures in type, many tables are printed by processes involving photography from manuscript prepared in other ways. The Yale zone catalogs, for example, have been prepared in this manner from typewritten manuscript. The zone published in 1925 was prepared with an ordinary typewriter, and the later zones with a special machine used only for this purpose. A number of typewriters have been produced in recent years with this application in mind. These machines give remarkably clear images, and one of them automatically regulates the force applied to each character.

The use of typewritten manuscript instead of loose type eliminates the necessity of repeatedly checking all the figures, since any change in the original manuscript is easily detected. The skill of the typist of course determines the accuracy of the original typing, and the problem should be roughly comparable to that of a compositor operating a monotype keyboard machine.

Since the adaptation of punched card accounting machines to scientific work there has been a great deal of copy for reproduction prepared on the printing units of these machines. ${ }^{1}$ The speed and accuracy of these printing units is phenomenal, but the printed results generally lack elegance. The individual characters are not as sharp and clear as printed characters and they are so spread out that the tables tend to be bulky. In 1941 a technique was developed in the Nautical Almanac Office which made it possible to overcome these difficulties. This method was used on the twelve volumes of the Air Almanac from 1942 to 1945 , and while the expert quickly notices the lack of perfection, the casual reader does not notice that the tables were not printed from type. The degree of economy and perfection attained in these tables is remarkable and has attracted widespread attention.

The outstanding feature of the method is that of printing alternate columns of the table on two successive runs of the machine, thus permitting the printing of twelve characters to the inch in the line instead of six. ${ }^{2}$ 
The line spacing was also changed for compactness. Special forms were ruled for the process by the Standard Register Company. The clarity of the individual characters was improved by careful examination of several details of the printing. The greatest improvement came from the use of carbon sheets instead of a carbon ribbon; this eliminated broken figures and shadows due to whipping of the ribbon. Careful selection of the grade of carbon paper and the softness of the platen greatly improved the clarity. A special device which applied additional mass behind the platen eliminated the multiple images due to bouncing. Painstaking adjustment of the typebars and spring tension by the Customer Engineers gave optimum registration.

While the method was considered only as a makeshift, it permitted production without special engineering and delay during a very critical period. The twelve volumes produced by this method have well served their purpose.

3. The New Machine. At the time the above method was adopted, another better method was proposed which has now materialized, and the machine is in operation. In this machine a special typewriter designed for printing tables is operated from punched cards. It combines the elegance of the finest typewriter with the accuracy and efficiency of the punched cards. This machine was built by the International Business Machines Corporation and installed in February, 1945. It was used in the production of the volumes of the Air Almanac for 1946, and the results are most gratifying.

The new machine was designed with maximum flexibility so as to print almost any kind of mathematical table. It is so arranged that most of the details of printing can be decided upon after the cards have been prepared, the principal exception being that the data must be printed in the order in which they appear on the card. The style and arrangement of the printing is determined by means of a flexible plugboard and a specially punched master card. Ample provision is made for both vertical and horizontal spacing, for the selection of type styles and symbols, for the suppression of insignificant zeros, and for the arbitrary suppression of any characters on the cards. Such operations as rounding the computed figures to the nearest unit, quarter unit, or other arbitrary division is accomplished with a small amount of gang punching.

The escapement of the typewriter permits spacing in the line in units of $\frac{1}{32}$ of an inch, and the standard ratchet on the platen gives line spacing in units of $\frac{1}{12}$ inch. The usual reduction in the photographic process will be to $\frac{2}{3}$. Three units to a figure thus gives tables which very closely resemble 8-point type, set 16 figures to the inch. The use of a platen ratchet with a different number of teeth would permit the simulation of "leaded" tables. The small figures printed with two units are equivalent to 6-point type, set 24 figures to the inch. The use of a different reduction ratio in the photographic process gives type results resembling those from different size type.

There are 88 characters which, after photographic reduction, give 8-point light figures, 8-point bold figures, 8- and 6-point figures on the half line (without moving platen), 6-point figures on the line, various kinds of decimals, plus and minus signs, etc., Roman numerals, and special symbols for the Air Almanac. Figure 1 shows the characters on the various typebars.

The selection of the basic style of the characters and the modifications of them were made with due consideration of the operation of the typewriter 
$\begin{array}{ccc}\text { NSO } 123456789 & 0123456789 . & \text { NS0123456789. } \\ \text { IVXLUndhms } & +-0123456789+010 "()\end{array}$

Figure 1. Characters on typewriter.

$488 \quad$ GREENWICH, P. M. 1941

\begin{tabular}{|c|c|c|c|c|c|c|c|c|c|c|c|c|}
\hline \multirow{2}{*}{$\begin{array}{r}\text { QCT } \\
1200 \\
10 \\
20 \\
30 \\
40 \\
50\end{array}$} & \multicolumn{3}{|c|}{ aHA $^{\odot}$ sUN $_{\text {Dec. }}$} & \multicolumn{2}{|c|}{ 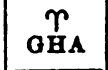 } & \multicolumn{3}{|c|}{ 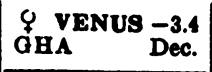 } & \multicolumn{4}{|c|}{\begin{tabular}{|cc}
$0^{7}$ MARs -1.8 \\
$\mathrm{GHA}$ & Dec.
\end{tabular}} \\
\hline & \begin{tabular}{rl}
$\circ$ & \multicolumn{1}{r}{} \\
0 & 00 \\
2 & 30 \\
5 & 00 \\
7 & 30 \\
10 & 00 \\
12 & 30
\end{tabular} & $\begin{array}{c}\circ \\
\text { N8 }\end{array}$ & 20 & $\begin{array}{l}\circ \\
160 \\
162 \\
165 \\
167 \\
170 \\
172\end{array}$ & $\begin{array}{l}1 \\
15 \\
46 \\
16 \\
47 \\
17 \\
48\end{array}$ & $\mid \begin{array}{cc}\circ & \prime \\
327 & 29 \\
329 & 59 \\
332 & 29 \\
334 & 59 \\
337 & 29 \\
339 & 59\end{array}$ & S6 & • & $\begin{array}{l}\circ \\
136 \\
139 \\
141 \\
144 \\
146 \\
149\end{array}$ & $\begin{array}{l}1 \\
49 \\
20 \\
50 \\
21 \\
51 \\
21\end{array}$ & N4 & है \\
\hline $\begin{array}{r}300 \\
10 \\
20 \\
30 \\
40 \\
50\end{array}$ & $\begin{array}{ll}15 & 00 \\
17 & 30 \\
20 & 00 \\
22 & 30 \\
25 & 00 \\
27 & 30\end{array}$ & N8 & 19 & $\begin{array}{l}175 \\
177 \\
180 \\
182 \\
185 \\
187\end{array}$ & $\begin{array}{l}18 \\
48 \\
19 \\
49 \\
20 \\
50\end{array}$ & $\mid \begin{array}{ll}342 & 28 \\
344 & 58 \\
347 & 28 \\
349 & 58 \\
352 & 28 \\
354 & 58\end{array}$ & S5 & & $\begin{array}{l}151 \\
154 \\
156 \\
159 \\
161 \\
164\end{array}$ & $\begin{array}{l}52 \\
22 \\
53 \\
23 \\
53 \\
24\end{array}$ & $\mathbf{N} 4$ & 67 \\
\hline
\end{tabular}

86 GREENWICH P. M. 1944

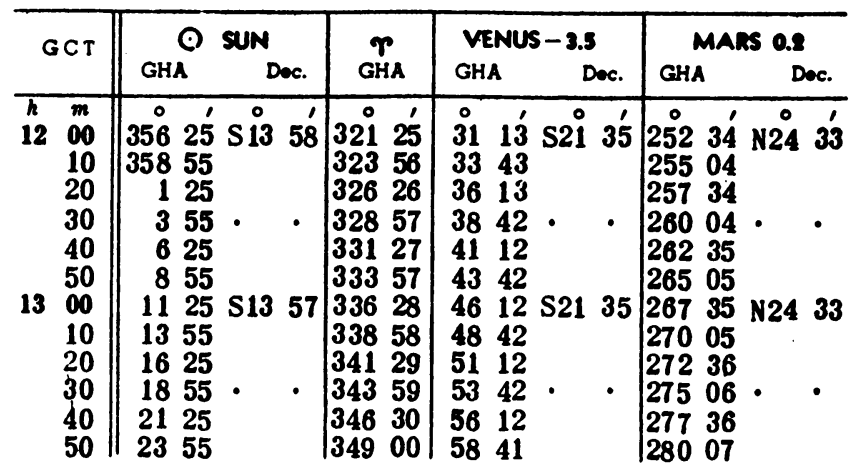

48 GREENWICH P. M. 1946

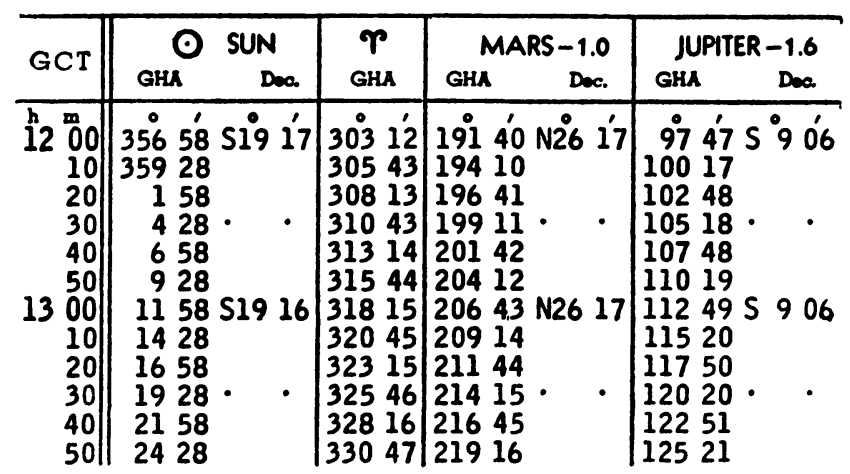

Figure 2. Reproductions from the American Air Almanac printed from: (upper) movable type, (middle) accounting machine record, (lower) electromatic machine. 
and the reproduction by photography. The primary consideration was that of legibility, though beauty was not ignored. For example, it is considered important to be able to recognize a numeral when a portion of it has been lost or when a black speck has been added to it in the printing process. The numerals and most of the letters are based on the characters known as Bell Gothic which were developed by the Mergenthaler Linotype Company for use in telephone directories.

The typewriter is an Electromatic Proportional Spacing Machine. This machine not only permits arbitrary spacing between the columns, but the printing is of unusual elegance. The Electromatic feature insures uniformity in the strength of the impressions. The arbitrary spacing between columns enables one to group figures into degrees, minutes, and seconds and also to space over single or double rules of various widths; added to this is the ability to print 8- and 6-point figures in 3-and 2-unit spaces; respectively, which permits printing with the compactness required in a wide variety of tables.

Figure 2 shows small specimens of the work produced by each of the three methods described above.

4. Printing Methods. Modern printing methods are highly developed and very reliable, but the process is not as nearly perfect as many suppose; eternal vigilance is the price of perfection in printing as well as in computing and proofreading. The fact that the final proofs or the manuscript for photographic reproduction are perfect does not insure perfection in the edition. It is necessary to examine press sheets selected according to the method of printing employed.

Printing by letterpress with electroplates is extremely reliable. One set of plates, barring accident, will print a large edition of several hundred thousand sheets. Battered plates are comparatively rare, so it is feasible to keep track of all such cases, and three press sheets, from the beginning, middle, and end of the run afford a reliable indication of the quality of the edition.

The lithographic or offset process is fast and economical, and under the best conditions gives results of remarkably fine quality. It is nevertheless a more delicate process and generally less reliable than the above method. The offset plates are cheap and easy to make but also easy to spoil; the result is a tendency to use numerous plates on a given job with consequent difficulty of control. The albumen plates are very satisfactory for small editions but require so many different plates for an edition the size of a recent issue of the Air Almanac that it is almost impossible to keep track of them. Even with "deep etched" plates, the chances of printing an entire edition from one set of plates are not good. The lithographic process is so sensitive to quality of materials and workmanship that during 1944 it was not considered feasible to print the Air Almanac by offset with the materials permitted by the War Production Board. Accordingly the last two volumes for 1945 were printed from electroplates made from line cuts. Another advantage of the electroplates is that the final proof is taken from the plate itself whereas in lithography the proof is taken from the negative and the plate or plates are prepared after the proofs are submitted.

A very common fallacy is the belief that lithographic plates and line cuts are exactly like the original, since they are made by a photographic 
process. This is erroneous for two reasons. In the first place different degrees of blackness on the manuscript do not show up on the negative in the same proportion. Thus a portion of a figure which looked gray on the manuscript may be entirely missing on the negative. In the second place considerable hand work is done on the negatives. In the lithographic process the retoucher paints over parts of the negative and clears out others. In the case of the line cut the photoengraver "routs" out part of the plate with an implement like a dentist's drill. It is true that with these processes, omissions are more probable than changes, but even these are not impossible.

5. Mechanical Proofreading. The application of the punched card technique has completely revolutionized the methods of proofreading in the Nautical Almanac Office both for tables set in type and for tables printed by methods involving photography; the new methods give revolutionary. dependability and economy. The conventional method of having a proofreader assume responsibility for the agreement of the copy and the proof has been abandoned. The proofs, but not the copy, are now given to a card punch operator whose only responsibility is to punch what she sees. A template is used which exposes only one line at a time, so there is no temptation to correct an error by looking up or down the column. These cards are then compared electrically with the cards from which the copy was prepared. This comparison is performed on one of the standard punched card machines at the rate of 6,000 cards per hour. Finally the various columns are differenced automatically on the accounting machine and the differences printed in such a manner that any error would be immediately apparent.

In the case of manuscript prepared on the accounting machine or on the new table printer, the results are so accurate that the line-cut proofs are examined only for general quality and legibility, no attention being paid to the figures themselves. The plate proofs only are subject to the rigorous methods above described.

6. Acknowledgments. The success of various phases of the work has been made possible by the cooperation of many people, including the following: the staff of the Government Printing Office, particularly Mr. R. W. Christie; the staff of the Nautical Almanac Office, especially Mr. G. M. Clemence and Mr. Jack Belzer; Mr. E. W. Gardinor and other engineers of the International Business Machines Corporation; Mr. C. H. Griffith, Mergenthaler Linotype Company.

Watson Scientific Computing Laboratory

U. S. Naval Observatory, Washington, D. C.

W. J. E. \&

RALPH F. HAUPT

${ }^{1}$ See W. J. Eckert, Punched Card Methods in Scientific Computation, The Thomas J. Watson Astronomical Computing Bureau, 1940, p. 106.

${ }^{2}$ See W. J. Eckert, "Air Almanacs," Sky and Telescope, v. 4, Nov. 1944, p. 12.

\section{RECENT MATHEMATICAL TABLES}

337[A, B, C, D, N, O].-Clemente Bonfigli a. Manuale Logaritmico Completo del Tecnico ad uso degli Ingegneri, Architetti, Geometri, Periti, ecc. con cinque cifre decimali Tavole logaritmiche dei numeri; Tavole log. delle Funzioni di angoli sessagesimali, centesimali e sessadecimali; Tavole 